\title{
Impact of Measurement Delay on State Estimation and Treatment Method
}

\author{
Jun Liu',a, Jiaqing Zhao ${ }^{2, b}$, Shuhai Feng ${ }^{1, c}$, Weijin Zhuang ${ }^{1}$ \\ ${ }^{1}$ China Electric Power Research Institute, Nanjing 210003, China \\ 2 Su Zhou Power Supply Company, Nanjing 215004, China \\ aliu-jun2@epri.sgcc.com.cn, bzhaojiaqing@126.com, cfengshuhai@epri.sgcc.com.cn
}

Keywords: State estimation; Measurement delay; SCADA with a time scale

Abstract: Measurement delay for state estimation outliers adverse consequences, affecting the right conclusion. In this paper, the possible measurement delay is given through the analysis of SCADA data acquisition and transmission process. Based on the verification platform of dispatching automation system, the measurement delay case is constructed. The influence of measurement delay on state estimation is analyzed quantitatively. A method based on unified time scalar in SCADA system is proposed. The influence of time error caused by various reasons on state estimation is solved.

\section{Introduction}

State estimation is based on the measures of Supervisory Control and Data Acquisition (SCADA) in dispatching automation system. Because the sampling equipment of different substations is not synchronized and there is no uniform measurement time scale, coupled with measurement delay in the process of transmission and multilevel data delivery, there is a great difference in time section which is based on the measurement of SCADA in state estimation. Especially when the system load changes quickly or the power grid has an impact load, the difference of the time section will lead to larger measurement errors. The errors of time section has a great influence on the accuracy of state estimation.

\section{Situation of measurement delay in dispatching automation system}

Commonly measurement acquisition technology adopts AC sampling, which can measure the two loop circuit that transformed by voltage and current transformer. After the calculation, the measurement of current, voltage, active and reactive power, frequency and power factor of $\mathrm{HV}$ electric equipment is obtained. Telemetry data from the device to the dispatching system generally experienced data acquisition, data transmission and data processing. The telemetry problem reflected in the dispatching system can be attributed to data incorrect and inconsistent latency.

\section{Measurement transmission}

Measurement data from acquisition to the dispatching automation system of the whole process needs to experience the prose of the substation sampling, substation data upload, master station receives data, master station processing the data and master station application and storage, etc. As shown in Fig.1, the time of the sampling data uploaded from the device to the sub-station is $\Delta t_{1}$, which is less than two seconds, and from the sub-station to direct mining system master data is $\Delta t_{2}$, which is less than 3 seconds, if the system is in better conditions, it will be less than one second, and the time from master-station receiving to the real-time database updates is $\Delta t_{3}+\Delta t_{4}$ seconds. Under the current level of technology, in the case of uploading the data from the subordinate station to the superior master station, every transponder will increase about 5 seconds of delay.

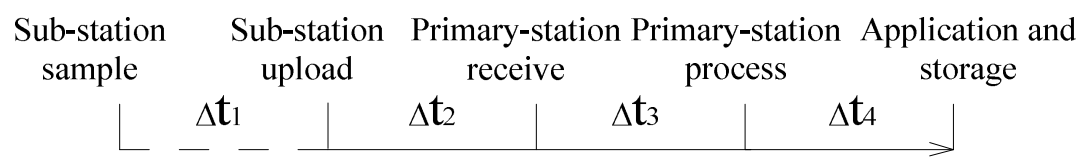

Fig.1 Key nodes of data transmission and processing 


\section{Fluctuation of overall load}

Due to the composition and characteristics of the various regions are identical, the load fluctuations of each region is also different. With the substantial increase of air conditioner, electric vehicles and other civilian load, a large number of institutions and schools and even some factory work concentrated in certain time periods, which lead to the overall load in many areas showing high volatility of periods, some areas in 10 to 30 minutes, its load fluctuations may reach 20 to $30 \%$ of its maximum daily load. Objectively, such a wide range of load fluctuations will be reflected in the power flow of volatility characteristics of the equipment, and different communication delay will also result in poor consistency of data used in state estimation.

\section{Impact load and intermittent energy}

Impact load (such as electric furnace steelmaking, heavy machinery, electric train, etc.) have a relatively clear variation characteristics, and its range can reach tens of mw, the change process can be completed in a few seconds, this leads to the section measuring data used in state estimation exist a few megabytes or even tens of megabytes of data inconsistency. And the intermittent and volatility the output of intermittent energy is very large. The fluctuations of the centralized access point power injection of impact load and intermittent power will cause a big change of the measured data of related equipment, and measurement time delay inconsistent will have great influence on the calculation results of state estimation.

\section{Equipment failures and improper operation}

When equipment is in maintenance and failure, a large number of equipment in the power grid will outage or be put into operation. Lines, transformers, generators and other equipment breaking and put into operation, the change of parameter of the Direct Current(DC) system or the DC system lockout and the actions of automatic device etc., will make power flow redistribution in a short time (within one second) then cause large changes in the power flow. The change of power grid operation will result in the data of rapid mutation and even the whole network data, and data transmission delay will lead to poor consistency of data used in state estimation. The accuracy of the results will also receive great influence.

\section{Influence analysis of measurement delay on state estimation}

In good running condition of the power system should not contain system error, under normal circumstances, a measured value from remote sensing devices and power grid parameter values can be described by true value plus a random error:

\section{Introduction of simulation platform in dispatching automation system}

The test and verification platform of dispatching automation system which is developed by China Electric Power Research Institute adopts PSS/E software as the computational engine. Experimental verification platform use the realistic simulation data to drive dispatching master system and organically integrated with dispatching master system. Then, study the change of statistical indicators of dispatching master system state estimation after setting different disturbance cases. Experimental verification platform consist of simulation layer, data layer, and EMS analog emulation layer, whose architecture diagram shown in Fig.2. 


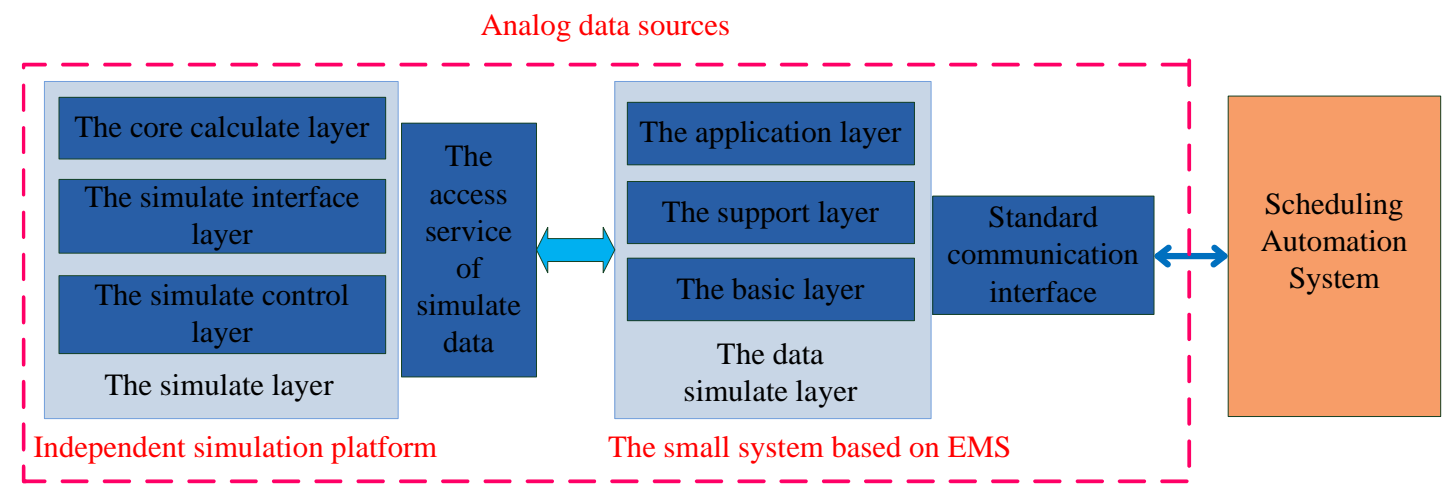

Fig.2 Architecture diagram of experimental verification platform

The flow chart of experimental verification about influence on state estimation owing to measurement delay is shown in Fig.3.

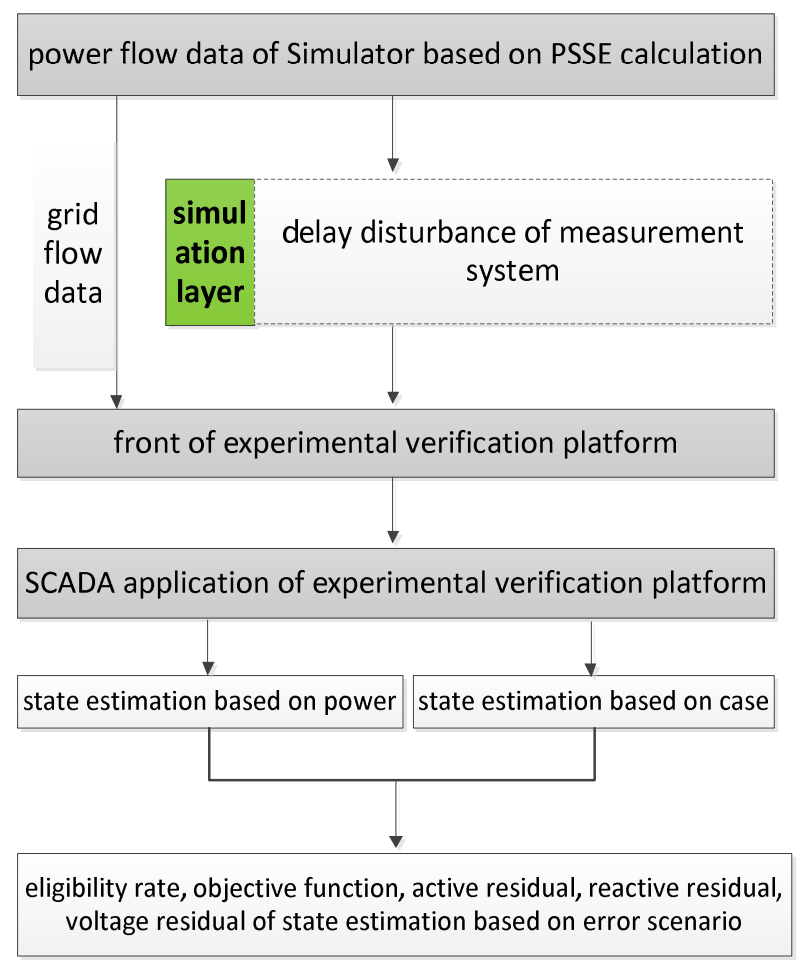

Fig.3 Flow chart of verification

The Dispatching Automation master system experiment platform use analog data to drive the data acquisition, data collection and other various application of the master system to realize the realistic simulation grid operation. Set various disturbances in actual simulation power grid and study the change of index in the master system state estimation.

The main steps are as follows:

Step 1) Simulation computer simulate the daily operation data of power grid;

Step 2) Data emulation layer to get the whole network operational data, simulate disturbance scenario and form various types of disturbance data;

Step 3) Send disturbance data, which is formed in data simulation layer, to the testing platform and the SCADA application;

Step 4) State estimation calculated according to the real-time data in SCADA. Compare and analyze the results of state estimations that based on power flow and measurement error scenario.

\section{Verification case}

The load of system change in different ramp rate, in this situation, due to the different features of direct mining station and data forwarding station delay, we set different delay interval ( 0 second, 5 seconds, 10 seconds and 15 seconds), which means the measured data is divided into four periods. According to the station area partition delay range, the substation in $220 \mathrm{kV}$ level, some is 15 seconds 
delay and some is 10 seconds delay; the substation in $500 \mathrm{kV}$ level, some is 5 seconds delay and some is 0 second delay. Simulate the time-delay data of state estimation in master station system, and compare the change of the related indexes.

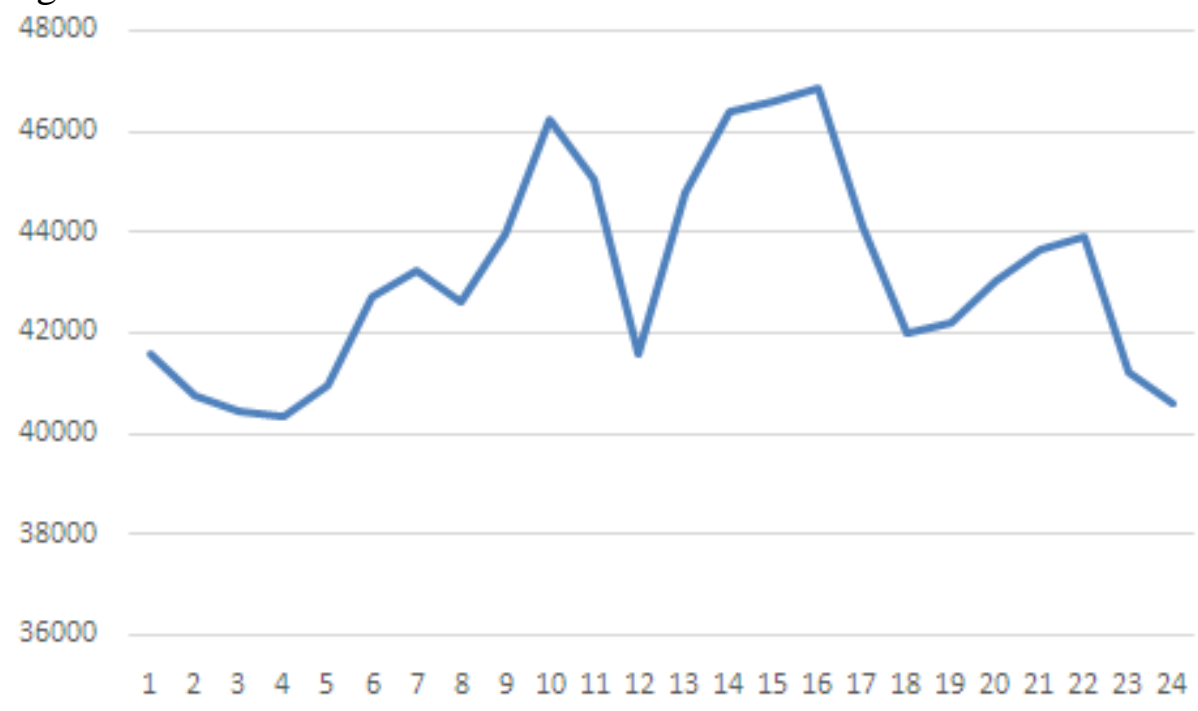

Fig.4 Curve of system load

In the test platform, change the two time interval of the load curve in simulation layer to achieve the load with different ramp rates.

Tab.1 The set table of comprehensive experiments

\begin{tabular}{|c|c|c|c|c|c|c|c|c|}
\hline $\begin{array}{c}\text { Load ramp } \\
\text { rate }\end{array}$ & $\begin{array}{r}\text { Measurem } \\
\text { ent points }\end{array}$ & Method & Test status & $\begin{array}{c}\text { Eligibility } \\
\text { rate }(\%)\end{array}$ & $\begin{array}{r}\text { Objective } \\
\text { function }\end{array}$ & $\begin{array}{l}\text { Active } \\
\text { residual }\end{array}$ & $\begin{array}{l}\text { Reactive } \\
\text { residual }\end{array}$ & $\begin{array}{l}\text { Voltage } \\
\text { residual }\end{array}$ \\
\hline \multirow{2}{*}{$\begin{array}{l}\text { Change rate } \\
\text { of system } \\
\text { load is } 1 \% \\
\text { in } 1 \text { minute }\end{array}$} & \multirow{2}{*}{10404} & M1 & $\begin{array}{c}\text { Before } \\
\text { Disturbance }\end{array}$ & 99.72 & 25.04 & 11.81 & 22.08 & 0.290 \\
\hline & & M2 & $\begin{array}{c}\text { After } \\
\text { Disturbance }\end{array}$ & 99.71 & 25.56 & 12.53 & 22.28 & 0.292 \\
\hline \multirow{2}{*}{$\begin{array}{l}\text { Change rate } \\
\text { of system } \\
\text { load is } 2 \% \\
\text { in } 1 \text { minute }\end{array}$} & \multirow{2}{*}{10405} & M1 & $\begin{array}{c}\text { Before } \\
\text { Disturbance }\end{array}$ & 99.70 & 24.95 & 11.51 & 22.13 & 0.294 \\
\hline & & M2 & $\begin{array}{c}\text { After } \\
\text { Disturbance }\end{array}$ & 99.65 & 26.55 & 14.52 & 22.22 & 0.290 \\
\hline \multirow{2}{*}{$\begin{array}{l}\text { Change rate } \\
\text { of system } \\
\text { load is 3\% } \\
\text { in } 1 \text { minute }\end{array}$} & \multirow{2}{*}{10405} & M1 & $\begin{array}{c}\text { Before } \\
\text { Disturbance }\end{array}$ & 99.70 & 24.90 & 11.01 & 22.34 & 0.289 \\
\hline & & M2 & $\begin{array}{c}\text { After } \\
\text { Disturbance }\end{array}$ & 99.60 & 29.32 & 19.02 & 22.32 & 0.292 \\
\hline \multirow{2}{*}{$\begin{array}{c}\text { Change rate } \\
\text { of system } \\
\text { load is } 4 \% \\
\text { in } 1 \text { minute }\end{array}$} & \multirow{2}{*}{10405} & M1 & $\begin{array}{c}\text { Before } \\
\text { Disturbance }\end{array}$ & 99.70 & 25.00 & 11.66 & 22.12 & 0.294 \\
\hline & & M2 & $\begin{array}{c}\text { After } \\
\text { Disturbance } \\
\end{array}$ & 99.59 & 31.77 & 22.59 & 22.34 & 0.286 \\
\hline \multirow{2}{*}{$\begin{array}{c}\text { Change rate } \\
\text { of system } \\
\text { load is } 5 \% \\
\text { in } 1 \text { minute }\end{array}$} & \multirow[t]{2}{*}{10405} & M1 & $\begin{array}{c}\text { Before } \\
\text { Disturbance } \\
\end{array}$ & 99.69 & 26.02 & 13.46 & 22.27 & 0.290 \\
\hline & & M2 & $\begin{array}{c}\text { After } \\
\text { Disturbance } \\
\end{array}$ & 99.52 & 35.89 & 27.71 & 22.81 & 0.302 \\
\hline \multirow{2}{*}{$\begin{array}{l}\text { Change rate } \\
\text { of system } \\
\text { load is } 6 \% \\
\text { in } 1 \text { minute }\end{array}$} & \multirow[t]{2}{*}{10405} & M1 & $\begin{array}{c}\text { Before } \\
\text { Disturbance }\end{array}$ & 99.72 & 24.85 & 11.27 & 22.15 & 0.300 \\
\hline & & M2 & $\begin{array}{c}\text { After } \\
\text { Disturbance }\end{array}$ & 99.52 & 47.20 & 39.96 & 25.13 & 0.321 \\
\hline \multirow{2}{*}{$\begin{array}{c}\text { Change rate } \\
\text { of system } \\
\text { load is } 7 \% \\
\text { in } 1 \text { minute }\end{array}$} & \multirow{2}{*}{10405} & M1 & $\begin{array}{c}\text { Before } \\
\text { Disturbance }\end{array}$ & 99.71 & 24.73 & 11.10 & 22.10 & 0.329 \\
\hline & & M2 & $\begin{array}{c}\text { After } \\
\text { Disturbance } \\
\end{array}$ & 99.52 & 49.06 & 42.32 & 24.81 & 0.330 \\
\hline
\end{tabular}


Different ramp rate of load make the data obtained in state estimation is not consistent with the real-time data. It is obvious that when increase the ramp rate of the load gradually, the latency of measured data will result in the increase of the imbalance power of the computing nodes, the consistency of the time section will be destroyed, the imbalance power of measurement system become bigger, thus make the qualified rate of state estimation decrease and residual become larger.

\section{Treatment method}

Aiming at the delay of data acquisition, it is difficult to provide the same time section measurement data for the calculation and analysis. SCADA system for scalar measurement at unity time is proposed. Though processing and storage of steady-state data with time markers, state estimation provides simultaneous steady-state real-time data cross sections. Thus it can establishing a spatio-temporal consistent information base for scheduling analysis decisions.

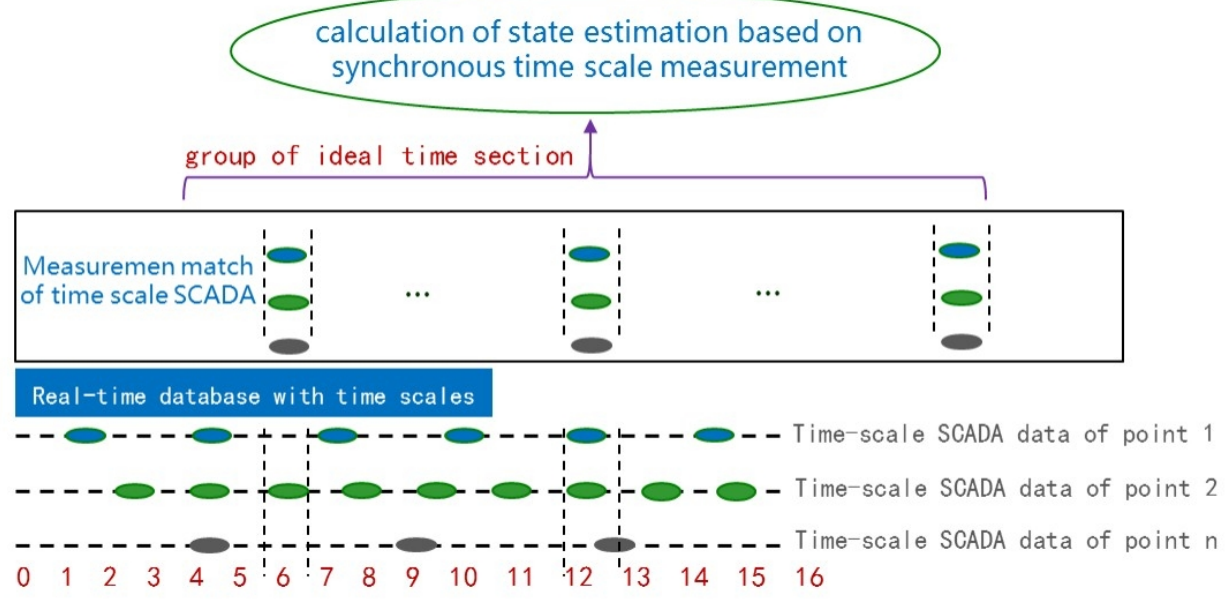

Fig.5 State estimation based on ideal section of time-scale SCADA

\section{Conclusion}

Through the simulation experiment of experimental verification platform, the paper analyzes the impact of measurement delay on the state estimation. It provide a method of state estimation based on time-scale SCADA measurement, and provide technical support for the improvement of safe and economic operation of the power grid.

\section{Acknowledgements}

This work was financially supported by the project of "Research on the mechanism and key technologies of steady-state data processing based on time scalar measurement" (DZ71-16-002) in China Electric Power Research Institute.

\section{References}

[1] Yu erkeng. State estimation of power system[M], Hydraulic and electric power press, 1985.

[2] Z. Fulin, R. Balasubramanian. "Bad data suppression in power system state estimation with a variable quadratic-constant criterion,” IEEE Trans. PAS, vol. PAS-104, Apr. 1985.

[3] A. S. Debs, R. E. Larson. A Dynamic Estimator for Tracking the State of a Power System[J]. IEEE Transactions on Power Apparatus and Systems, 1970, PAS-89(7): 1670-1678.

[4] E. Handschin, F. C. Schweppe, J. Kohlas, and A. Fiechter, "Bad data analysis for power system state estimation,” IEEE Trans. PAS, vol. PAS-94, pp. 329-337, Mar/Apr. 1975. 